\title{
Effects of acute lying and sleep deprivation on metabolic and inflammatory responses of lactating dairy cows
}

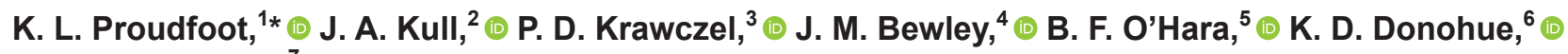 \\ and G. M. Pighetti ${ }^{7 *}$ (1) \\ ${ }^{1}$ Health Management, University of Prince Edward Island, Charlottetown, PE, Canada C1B1L2 \\ ${ }^{2}$ USDA, Beltsville, MD, 20705 \\ ${ }^{3}$ Department of Agricultural Sciences, University of Helsinki, Helsinki, Finland FI-00014 \\ ${ }^{4}$ Holstein Association USA Inc., Brattleboro, VT, 05301 \\ ${ }^{5}$ Department of Biology, University of Kentucky, Lexington, 40506 \\ ${ }^{6}$ Department of Electrical and Computer Engineering, University of Kentucky, Lexington, 40506 \\ ${ }^{7}$ Department of Animal Science, University of Tennessee, Knoxville, 37996
}

\section{ABSTRACT}

Dairy cows that are restricted from lying down have a reduced ability to sleep. In other species, sleep loss is a key risk factor for disease, mediated by changes in metabolic and inflammatory responses. The cumulative effect of lying and sleep deprivation on cow health is unknown. The objective was to determine the effects of lying and sleep deprivation on metabolic and inflammatory responses of dairy cows. Data were collected from 8 multiparous and 4 primiparous lactating cows $(199 \pm 44 \mathrm{~d}$ in milk, $77 \pm 30 \mathrm{~d}$ pregnant; mean \pm standard deviation) enrolled in a study using a crossover design. Each cow was exposed to 2 treatments meant to induce sleep loss: (1) human disturbance (imposed by researchers making noise or physical contact when the cow's posture suggested sleep) and (2) lying deprivation (imposed by a wooden grid placed on the pen floor). Cows experienced a $24-\mathrm{h}$ baseline period $(\mathrm{d}-1)$ followed by a 24 -h treatment period (d 0), with a $12-\mathrm{d}$ washout period between treatments. Baseline and treatment periods were imposed from 2100 to $2059 \mathrm{~h}$. Cows were housed in individual pens during the acclimation period ( $\mathrm{d}-3$ and -2$), \mathrm{d}-1$, and $\mathrm{d} 0$. Nonesterified fatty acid and glucose concentrations were measured at 0300, 0900, 1500, and $2059 \mathrm{~h}$ on d -1 and 0. Proinflammatory cytokine mRNA [tumor necrosis factor $(T N F)$, interleukin-1B $(I L 1 B)$, and interleukin-6 (IL6)] abundance in whole-blood leukocytes, both nonstimulated and stimulated with lipopolysaccharide, were assessed at $2059 \mathrm{~h}$ on $\mathrm{d}-1$ (end of baseline) and $\mathrm{d} 0$ (end of treatment). Nonesterified fatty acids and glucose varied by time of day but were not affected by treatment or

Received July 21, 2020.

Accepted November 18, 2020.

*Corresponding authors: kproudfoot@upei.ca and pighetti@utk.edu day. The abundances of $T N F$ and $I L 1 B$ from both stimulated and nonstimulated cells were higher following 24 $\mathrm{h}$ of lying deprivation (d 0) compared with baseline (d -1 ). Abundance of $I L 6$ was increased in nonstimulated cells after lying deprivation compared with baseline. In contrast, human disturbance for $24 \mathrm{~h}$ did not alter $T N F, I L 1 B$, or IL 6 abundance relative to baseline levels. These results suggest that a short period of lying deprivation generally increases inflammatory responses but not metabolic responses.

Key words: inflammation, health, stress

\section{INTRODUCTION}

Dairy cows experience metabolic and infectious diseases that compromise their welfare (reviewed by Overton et al., 2017; Galvão, 2018). Researchers have identified some risk factors for illness, including genetic, physiological, and behavioral changes at the cow level (e.g., Huzzey et al., 2007; Ospina et al., 2010), but it remains unclear why some cows are more susceptible to illness than others. In the human literature, researchers have identified sleep as a key factor related to disease risk (reviewed by Motivala and Irwin, 2007). For example, several studies in humans have identified sleep loss as a risk factor for mortality (Grandner et al., 2010), diabetes (Gottlieb et al., 2005), cardiovascular disease (Sabanayagam and Shankar, 2010), and infectious diseases such as the common cold (Cohen et al., 2009). Despite the clear relationship between sleep loss and health in humans, no research to our knowledge has determined the effect of sleep loss on disease risk in dairy cattle.

Researchers have characterized sleep in dairy cows throughout the lactation cycle (Ternman et al., 2012, 2019). Cows, like humans, undergo 2 phases of sleep: non-rapid eye movement (NREM) and rapid eye 
movement (REM; Ternman et al., 2012, 2019). Unlike humans, cows spend a considerable amount of time in a drowsing phase between NREM sleep and alert wakefulness (Ruckebusch, 1972). Researchers have found that cows sleep or drowse in short bouts throughout the day (Ternman et al., 2012) for a total of about 1.5 to $3 \mathrm{~h} / \mathrm{d}$ in NREM sleep, 30 min to $1 \mathrm{~h} / \mathrm{d}$ in REM sleep, and 1 to $7 \mathrm{~h} / \mathrm{d}$ drowsing, depending on the stage of lactation and the methodology used to measure these vigilance states (Rucklebush, 1972; Ternman et al., 2019). Thus, sleep is quite different in dairy cows compared with humans, suggesting a need to determine how sleep loss may affect these animals differently.

In a recent study by our group, we investigated the effect of acute sleep and lying deprivation on the behavior of dairy cows (Kull et al., 2019). Over a 24-h period, cows were disturbed from sleeping using human interference (noise or physical contact when the cow's posture suggested sleep) and deprived of lying using a grid placed on the pen floor using a crossover design. Lying time was lower for both treatments during the 24-h period compared with a baseline day, and it took cows 2 and $4 \mathrm{~d}$ to recover their lying time when they were disturbed or deprived of lying, respectively. Cows were also monitored for sleep using electroencephalography (EEG); when deprived of the ability to lie down, cows had lower REM and NREM sleep compared with a baseline period, but there was no effect of the human disturbance treatment on the EEG data. These results were part of a larger experiment aiming to understanding the possible link between sleep and lying deprivation and cow health.

The effect of sleep and lying deprivation on the health of dairy cows has not been well established and is important to understand relative to on-farm conditions such as overcrowding, poor stall design or management, heat stress, and transport stress. In humans and laboratory rodents, sleep loss causes a proinflammatory state, characterized by an increase in proinflammatory cytokines (Hu et al., 2003; Irwin et al., 2006; van Leeuwen et al., 2009; Chennaoui et al., 2015). Although these inflammatory cytokines are critical for immunity, chronic low-grade inflammation can result in immune and metabolic dysfunction in both humans and dairy cattle (McPherson, 2001; Bradford et al., 2015). Sleep is also important for regulating energy expenditure and metabolism; for example, human patients with 1 night of partial sleep loss $(4 \mathrm{~h})$ showed lower glucose tolerance and higher insulin-induced nonesterified fatty acids (NEFA), although they showed no changes in basal levels (Donga et al., 2010). The effect of acute sleep loss on inflammatory and metabolic responses in cattle remains unknown.
There is also a lack of knowledge about how lying deprivation affects metabolic and inflammatory responses in dairy cows. Lying time has long been considered an important measurement of a cow's comfort in her environment and is a highly prioritized behavior (Metz, 1985; Munksgaard and Simonsen, 1996). A reduction in lying time can increase a cow's risk of lameness (Ito et al., 2010), but the physiological mechanism linking standing time to lameness is not well understood. In other species, long-duration and high-intensity exercise can increase an inflammatory response, measured using proinflammatory cytokines (reviewed by Powers and Jackson, 2008). Thus, research is still needed to determine the effect of the potential cumulative effect of sleep and lying deprivation on metabolic and inflammatory responses in dairy cattle.

Determining the effect of acute sleep and lying deprivation on physiological indicators of health in cattle, including inflammatory and metabolic responses, is a critical first step in understanding the consequences of management strategies that may result in reduced lying time and sleep loss. The objective of this study was to determine the effect of $24 \mathrm{~h}$ of human disturbance or lying deprivation on metabolic (NEFA and glucose) and inflammatory [proinflammatory cytokines: tumor necrosis factor (TNF) and interleukin (IL1B and IL6)] responses. We had originally predicted that cows in both treatments would show shifts in energy balance and inflammatory responses compared with baseline; however, after the results from Kull et al. (2019) showed that only lying deprivation affected EEG data, we expected that the lying deprivation treatment would have the greatest effect on these responses.

\section{MATERIALS AND METHODS}

This study was conducted at the University of Tennessee's Little River Animal and Environmental Unit (Walland, TN) during April and May 2016. All animal procedures were approved by the University of Tennessee Institutional Animal Care and Use Committee.

\section{Animals, Housing, and Management}

This experiment was part of a larger study assessing the effect of lying and sleep deprivation on cow behavior and physiology; Kull et al. (2019) described the same methodology used in this study and the results of the behavioral analysis and milk yield. Twelve pregnant, mid- to late-lactation Holstein dairy cows were enrolled in the study $(199 \pm 44$ DIM; $77 \pm 30 \mathrm{~d}$ pregnant). Before the study, cows were group housed in deep-bedded sand freestall pens. During the 4-d 
study period, cows were housed individually in a 4.11 $\times 3.32-\mathrm{m}$ pen with a mattress; in these pens, cows were physically separated from the herd but had visual and olfactory contact with the main herd and could make nose-to-nose contact with cows in a neighboring pen. Individual pens were cleaned daily with a chlorhexidine solution (Durvet Inc., Blue Springs, MO) and water at $0700 \mathrm{~h}$. Additionally, feces were removed manually throughout the day to maintain pen and cow hygiene.

Fresh water and a TMR were available ad libitum for cows throughout the study. The TMR comprised $60 \%$ corn silage, $25 \%$ pelleted premix grain concentrate, $12 \%$ small grain silage, and 3\% dry hay. Cows were milked twice daily starting at 0700 and $1730 \mathrm{~h}$ in a double- 8 herringbone milking parlor (BouMatic, Madison, WI).

\section{Sample Size and Enrollment Criteria}

A power analysis was used to determine an adequate sample size for assessing our objective. No research to our knowledge has assessed the effect of sleep or lying deprivation on physiological measurements in cattle; thus, we used data collected from humans for our sample size calculation. Based on results from Irwin et al. (2006), we expect an approximate 2- to 3 -fold increase in proinflammatory cytokine gene expression due to sleep loss. If we assume the more conservative increase (2-fold increase) with variation of $1.25,12$ cows per treatment group were required to detect significance at the 0.05 level (2-tailed test) with $>85 \%$ power. To be included in the study, cows must have been pregnant and in mid to late lactation (90-150 DIM) to avoid any potential differences in sleep due to stage of lactation and pregnancy (Ternman et al., 2019).

The response of cows to humans was also measured and included as an enrollment criterion, as the study involved intensive human contact. We excluded cows that showed behavioral signs of stress when handled by a human caretaker. Cow response to humans was evaluated using 2 tests: an approachability test and a brush test. For the approachability test, a researcher slowly approached the cow with one arm extended and observed the cow's reaction (Lensink et al., 2003). Cows were scored based on the 1-to- 4 scale described by Lensink et al. (2003; 1 = cow allowed physical contact, 4 $=$ the cow strongly withdrew from the researcher). If the cow remained still and allowed physical contact or approached the researcher (a score of 1 or 2), the cow was considered suitable for the study. For the brush test, the cow's head and neck area were brushed by a researcher, specifically in the regions where the EEG equipment would be placed (Lensink et al., 2003; Ternman et al., 2014). Cows were scored on the same 1-to-4 scale as the approachability test. If the cow did not pull away or only slightly withdrew when brushing occurred (a score of 1 or 2 ), she was considered an acceptable candidate for the study.

Finally, to limit any effects of current health status on our outcomes, white blood cell counts (WBC) were measured on the pool of cows that met our first 2 criteria. To measure WBC, blood was collected via the coccygeal vein using a sterile needle (1-1.5 in. $\times$ $16 \mathrm{G})$ while cows were restrained in a headlock. Estimation of WBC differential was conducted using the Wright-Giemsa method with the Fisher HealthCare Protocol HEMA 3 Fixative and solutions kit following the manufacturer's instructions (Thermo Fisher Scientific, Waltham, MA). Microscope slides (Thermo Fisher Scientific) were read following the procedure by Levkut et al. (2002). To be included in the study, cows must have had low WBC $(\leq 12.6$; Schalm, 1961). All 12 cows enrolled in the study met these inclusion criteria.

\section{Experimental Design and Treatments}

The study was a within-cow crossover design with rolling enrollment and included 2 treatments that aimed to induce sleep loss: (1) human disturbance and (2) lying deprivation. Treatments were designed to isolate sleep deprivation from the combined effects of lying and sleep deprivation. The study included a 2-d habituation period ( $\mathrm{d}-3$ and -2$)$, a 1-d baseline period $(\mathrm{d}-1)$, a 1 -d treatment period $(24 \mathrm{~h}$ of either human disturbance or lying deprivation; d 0 ), and a 12 -d washout period between treatments. The order of treatments was randomized for each cow using Excel (Microsoft Inc., Redmond, WA); one researcher (J. Kull) randomized the order of treatments. We ran 2 cows in separate, adjacent pens through the experiment at one time; cows were paired based on parity, DIM, and production. Within a pair, one cow received the sleep deprivation treatment and the other cow received the lying deprivation treatment. After the pair's first treatment, they returned to their home deep-bedded sand freestall pen for a 12-d washout period before returning to an individual pen for their second treatment.

Each pair of cows was moved into the experimental pen at the start of the habituation period. We used the habituation period to help the cows acclimate to the new environment (individual pen with a mattress) due to differences from their previous housing (group freestall with deep-bedded sand stalls).

Following the habituation period, a baseline period occurred from 2100 to $2059 \mathrm{~h}$. At the start of this period, the cows were fitted with the electrophysiological equipment that collected EEG, electrooculography, and 
electromyography data (BioRadio, Great Lakes Neurotechnologies, Cleveland, OH); see Kull et al. (2019) for a detailed description of this equipment and how it was attached to each cow. The EEG data were collected continuously throughout baseline and treatment periods.

During the treatment period, each treatment (human disturbance or lying deprivation) occurred from 2100 to $2059 \mathrm{~h}$. To deprive cows of sleep using human disturbance, cows were allowed to lie down but were continuously monitored to ensure they remained awake and alert. A researcher was in the alley directly adjacent to the study pen and monitored the cows through a window without causing the cow too much disturbance. If the cow's posture suggested the onset of sleep (e.g., lateral recumbency or sternal recumbency with closed eyes), the observer would approach the pen and use a rattle paddle to create noise. This process was effective approximately $90 \%$ of the time in causing cows to open their eyes and occasionally raise their head. If this did not occur, the next step was to open the gate and enter the pen. If this was ineffective, the last strategy was to approach the cow and stroke her neck with a firm touch. Overall, none of these strategies startled the cows and may reflect the less nervous nature of these cows and acclimation to human interactions. To deprive cows of lying, a wooden grid was placed on the pen floor, preventing cows from assuming a recumbent position (Schütz et al., 2008; Kull et al., 2019). If cows attempted to lie during treatment, a researcher would gently encourage her to stand up.

\section{Physiological Measures}

Blood Sampling. Blood samples were taken from each cow during the baseline and treatment period every $6 \mathrm{~h}( \pm 1 \mathrm{~h})$ at 0300, 0900, 1500, and $2059 \mathrm{~h}$. During each sampling period, the cow was restrained in a headlock. Blood was collected via the coccygeal vessels using a sterile needle $(1-1.5$ in. $\times 16 \mathrm{G})$. Blood was centrifuged at a speed of $3,000 \times g$ at $4^{\circ} \mathrm{C}$ for $10 \mathrm{~min}$; serum was harvested and stored in a $-80^{\circ} \mathrm{C}$ freezer for later analysis (Alhussien et al., 2015). Researchers were blinded to treatments when performing the following blood analyses.

Proinflammatory Cytokines. Proinflammatory cytokines (TNF, IL1B, and IL6) were measured from blood leukocytes sampled at the $2059 \mathrm{~h}$ sampling time at the end of both the baseline and treatment periods. Whole blood $(5 \mathrm{~mL})$ was incubated with Dulbecco's modified Eagle medium added $(25 \mu \mathrm{L})$ or LPS $(25 \mu \mathrm{L}$; final concentration of $5 \mu \mathrm{g} / \mathrm{mL}$ of blood; Escherichia coli 0111:B4 LPS, Sigma L4391, Sigma-Aldrich, St. Louis, MO) for $3.5 \mathrm{~h}$ at $37^{\circ} \mathrm{C}$ (Røntved et al., 2005). $T N F, I L 1 B$, and $I L 6$ mRNA expression was measured via reverse-transcription quantitative PCR (RTqPCR). The RNA was initially isolated and stabilized using a LeukoLOCK kit (Thermo Fisher Scientific) and was purified following the manufacturer's instructions (Thermo Fisher Scientific). Later, RNA quality and quantity were assessed using an Experion capillary electrophoresis station (Bio-Rad, Hercules, CA) with Experion StdSens RNA chips and reagents (7007154, Bio-Rad). Total RNA $(1.0 \mu \mathrm{g})$ was heat denatured at $70^{\circ} \mathrm{C}$ for 2 min before reverse transcriptase. The RNA was reverse transcribed into cDNA using GoScript reverse transcriptase (Promega, Madison, WI) following the manufacturer's instructions with RNasin ribonuclease inhibitor. The adapters used to prime the reverse transcription were oligo dT (15-mers) and random hexamers at a final concentration of $12.5 \mathrm{ng} / \mu \mathrm{L}$ each. RNasin was used at a concentration of $1 \mathrm{U} / \mu \mathrm{L}$, and the enzyme used had a final concentration of $8 \mathrm{U} / \mu \mathrm{L}$. Samples were incubated in the thermocycler (iCycler, Bio-Rad) at $20^{\circ} \mathrm{C}$ for $5 \mathrm{~min}, 42^{\circ} \mathrm{C}$ for $1 \mathrm{~h}$, and $85^{\circ} \mathrm{C}$ for 5 min and then held at $4^{\circ} \mathrm{C}$.

Last, real-time quantitative $\mathrm{PCR}$ was performed on a QuantStudio6 (Applied Biosystems, Foster City, CA) using Power SYBR Green Master Mix (Applied Biosystems). Gene-specific primers were designed using Primer3 (Untergasser et al., 2012) and ordered from IDT (Coralville, IA; Table 1). The PCR for each gene was run in triplicate in a 384-well plate and included 2 $\mu \mathrm{L}$ of $\mathrm{cDNA}$, each specific forward and reverse primer (final concentration $=100 \mathrm{n} M$ ), and $1 \times$ Sybr Green master mix in a final volume of $5 \mu \mathrm{L}$. Conditions of the PCR included an initial $2 \mathrm{~min}$ at $50^{\circ} \mathrm{C}$, then $95^{\circ} \mathrm{C}$ for $10 \mathrm{~min}$, followed by 50 cycles of $95^{\circ} \mathrm{C}$ for $15 \mathrm{~s}$ and $60^{\circ} \mathrm{C}$ for 1 min. A melt curve was run to assess specificity of reaction. Cytokine gene expression was relative to the expression of 2 reference genes that were selected from a pool of 9 genes that were most consistent with the sample type ( $Y W H A Z$ and S24). An interrun calibrator was created by pooling an equal volume of all samples. Reference genes and an interrun calibrator were included on all plates. The mean value for each triplicate sample was normalized to the geometric mean of the reference genes as outlined previously by Vandesompele et al. (2002) using the formula $\Delta \mathrm{Cq}=\mathrm{Cq}$ target Cq reference (Livak and Schmittgen, 2001), where Cq $=$ the cycle that crossed the threshold line. The $\Delta \mathrm{Cq}$ values within a plate also were normalized to the $\Delta \mathrm{Cq}$ values of the interrun calibrator to remove technical variability between plates, resulting in $\Delta \Delta \mathrm{Cq}$. By using 
the formula $\mathrm{X}=2^{(-\Delta \Delta \mathrm{Cq})}$, data were linearized into a value representing expression of the target gene relative to the 2 reference genes (Livak and Schmittgen, 2001).

Metabolic Indicators. Nonesterified fatty acids and glucose were measured at 0300, 0900, 1500, and $2059 \mathrm{~h}$ during the baseline and treatment periods. To measure NEFA, we used a Wako commercial kit (Wako Chemicals, Richmond, VA) and followed the manufacturer's instructions except for modification of the volume of reagents A and B to 130 and $65 \mu \mathrm{L}$, respectively. Similarly, glucose samples were run in duplicate using the Glucose Hexokinase Reagent Kit (Thermo Electron Corp., Waltham, MA) following the manufacturer's instructions. The intra- and interassay coefficients of variation were, respectively, 1.61 and $1.99 \%$ for NEFA and 4.05 and $4.13 \%$ for glucose.

Sleep States. The data collected from the EEG attached to each cow were used to calculate the amount of REM, NREM, and drowsing cows experienced during the baseline and treatment periods for a total of 4 $\mathrm{d} /$ cow $(2 \mathrm{~d} /$ cow per treatment). These data are used to specifically compare with our physiological data; treatment comparisons for these data are presented in Kull et al. (2019).

\section{Statistical Analysis}

All data were analyzed in SAS 9.4 (SAS Institute Inc., Carry, NC) using the cow as the experimental unit. Data were screened for normality and heterogeneity of residuals. Statistical significance was declared at $P<0.05$, and trends were declared at $P<0.10$.

To determine the effect of our treatments on proinflammatory cytokines, a mixed model ANOVA (PROC GLIMMIX) was used. All data were log transformed to generate a normal distribution. The model included the fixed effects of time ( $d-1$ or 0$)$, treatment (human disturbance or lying deprivation), and LPS stimulation (stimulated or unstimulated) as fixed effects and all possible interactions of those fixed effects. Random effects included cow, order of treatment, and the interactions of cow, order, and treatment. An autoregressive covariance structure was used to account for withinanimal variance over time.

To determine the effect of treatments on metabolic responses, a mixed model ANOVA (PROC GLIMMIX) was used. The model included the fixed effects of time ( $\mathrm{d}-1$ or 0$)$, treatment (human disturbance or lying deprivation), hour (0300, 0900, 1500, or $2059 \mathrm{~h}$ ), and all possible interactions. Random effects included cow, order of treatment, and the interactions of cow, order, and treatment. An autoregressive covariance structure was used to account for within-animal variance of glucose with hour of sampling. A compound symmetry covariance structure was used to account for within-animal variance of NEFA with hour of sampling because the minimum variance estimates for starting values failed when using an autoregressive structure.

We had specific predictions about the effect of our treatments (human disturbance and lying deprivation) on inflammatory and metabolic responses; thus, post hoc comparisons were made between days $(\mathrm{d}-1$ and 0 ) for each treatment separately. In addition, separate analyses were done for our cytokine data based on LPS stimulation (stimulated vs. unstimulated).

\section{RESULTS}

\section{Proinflammatory Cytokines}

Overall, we detected higher $T N F$ and $I L 1 B$ but not IL 6 by whole-blood leukocytes independent of LPS stimulation status during the lying deprivation treatment day (d 0) compared with baseline $(\mathrm{d}-1 ; P=$ $0.005,0.006$, and 0.13 , respectively). In contrast, we did not detect any differences between treatment and baseline days for $T N F, I L 1 B$, or $I L 6$ when cows were on

Table 1. Primer sequences for reference and target genes used in the current study

\begin{tabular}{|c|c|c|}
\hline Gene & GenBank ID & Primer sequence $\left(5^{\prime}-3^{\prime}\right)$ \\
\hline \multicolumn{3}{|l|}{ Target genes } \\
\hline \multirow[t]{2}{*}{$I L 6$} & NM_173923.2 & Forward: CACCCCAGGCAGACTACTTC \\
\hline & & Reverse: CCAGAAGACCAGCAGTGGTT \\
\hline \multirow[t]{2}{*}{$I L 1 B$} & NM_174093.1 & Forward: CAACCGTACCTGAACCCATCA \\
\hline & & Reverse: GCTGGTTGTCTTCCAGCTTCA \\
\hline \multirow[t]{2}{*}{$T N F$} & NM_173966.3 & Forward: CGGTGGTGGGACTCGTATG \\
\hline & & Reverse: GCTGGTTGTCTTCCAGCTTCA \\
\hline \multicolumn{3}{|l|}{ Reference genes } \\
\hline \multirow{2}{*}{$Y W H A Z$} & GU817014.1 & Forward: GCATCCCACAGACTATTTCC \\
\hline & & Reverse: GCAAAGACAATGACAGACCA \\
\hline \multirow[t]{2}{*}{ RPS24 } & XM_005226403.2 & Forward: TTTGCCAGCACCAACGTTG \\
\hline & & Reverse: AAGGAACGCAAGAACAGAATGAA \\
\hline
\end{tabular}


Table 2. Relative levels ${ }^{1}$ of proinflammatory cytokines produced by peripheral whole-blood leukocytes in the absence $(-)$ or presence $(+)$ of LPS stimulation

\begin{tabular}{|c|c|c|c|c|c|c|c|}
\hline Cytokine & $\begin{array}{l}\text { LPS } \\
\text { stimulation }^{2}\end{array}$ & \multicolumn{2}{|c|}{ Lying deprivation } & $P$-value & \multicolumn{2}{|c|}{ Human disturbance } & $P$-value \\
\hline$T N F$ & - LPS & $2.10^{\mathrm{b}}$ & $3.67^{\mathrm{a}}$ & 0.02 & 2.26 & 2.73 & 0.39 \\
\hline \multirow[t]{2}{*}{$I L 1 B$} & - LPS & $0.44^{\mathrm{c}}$ & $0.82^{\mathrm{d}}$ & 0.06 & 0.37 & 0.40 & 0.31 \\
\hline & + LPS & $1.81^{\mathrm{b}}$ & $2.51^{\mathrm{a}}$ & 0.04 & 2.17 & 2.24 & 0.30 \\
\hline IL6 & - LPS & $0.96^{\mathrm{b}}$ & $1.69^{\mathrm{a}}$ & 0.03 & 1.27 & 1.22 & 0.60 \\
\hline
\end{tabular}

\footnotetext{
${ }^{\mathrm{a}, \mathrm{b}}$ Values within a row with different superscripts differ by day within a cytokine, LPS stimulation, and treatment pairing $(P<0.05)$.

${ }^{\mathrm{c}, \mathrm{d}}$ Values within a row with different superscripts differ by day within a cytokine, LPS stimulation, and treatment pairing $(P<0.10)$.

${ }^{1}$ Values are relative to 2 reference genes ( $Y W H A Z$ and RPS24). Relative gene expression values are expressed as LSM and SE.

${ }^{2}$ Cows were lying deprived or disturbed for $24 \mathrm{~h}(\mathrm{~d} 0)$ compared with a baseline period the day before $(\mathrm{d}-1)$.
}

the human disturbance treatment $(P=0.20,0.86$, and 0.77 , respectively).

For all 3 cytokines there was an effect of LPS, whereby stimulation with LPS increased values for $I L 1 B(P$ $<0.0001)$, TNF $(P=0.02)$, and IL6 $(P \leq 0.0001)$ compared with nonstimulated values. When the data were analyzed by stimulation status, we found that for nonstimulated blood leukocytes, TNF $(P=0.02)$ and IL6 $(P=0.03)$ were increased and $I L 1 B(P=0.06)$ tended to increase with lying deprivation compared with baseline ( $\mathrm{d}-1$; Table 2$)$. We did not detect any differences between treatment and baseline periods (d -1) for nonstimulated blood leukocytes following the human disturbance treatment (d 0). The LPSstimulated blood leukocytes from lying-deprived cows also displayed higher TNF $(P=0.05)$ and $I L 1 B(P=$ $0.04)$ but not $I L 6(P=0.80)$ gene expression after lying deprivation ( $\mathrm{d} 0)$ compared with the baseline $(\mathrm{d}-1$; Figure 1). In contrast, human disturbance displayed similar levels of stimulated $T N F, I L 1 B$, and $I L 6$ on the 2 collection days $(P \geq 0.30)$.

\section{Metabolic Indicators}

Concentrations of NEFA and glucose did not differ by day, treatment, or their interaction $(P>0.05)$. However, both NEFA and glucose differed depending on the hour of collection $(P \leq 0.03$; Figure 2$)$.

\section{DISCUSSION}

The objective of this study was to determine the effects of acute sleep loss caused by human disturbance and lying deprivation on indicators of metabolism and inflammatory responses of peripheral blood leukocytes in dairy cows. We found that our treatments did not affect metabolic indicators (NEFA and glucose), but lying deprivation generally increased nonstimulated and stimulated expression of inflammatory cytokines.

An important consideration before interpreting the results of this study is the effect of our treatments on sleep measure using the EEG. Kull et al. (2019) described the amount of REM, NREM, and drowsing that occurred during both treatments (sleep loss caused by human disturbance and lying deprivation). Lying deprivation caused a significant reduction in all sleep states (REM, NREM, drowsing); however, human disturbance caused only minor arithmetic differences from the baseline period. Thus, cows were able to maintain sleep despite our efforts to keep them awake using human disturbance. These findings may explain why we saw larger effects of lying deprivation on inflammatory markers compared with human disturbance, discussed in more depth below.

As indicators of host inflammation, we assessed the expression of proinflammatory cytokines TNF, IL1B, and IL 6 by whole-blood leukocytes. The potential utility of this strategy was demonstrated in humans where high sera levels of C-reactive protein, a proinflammatory biomarker, were significantly associated with LPSstimulated expression of TNF and IL 6 by whole-blood leukocytes before and after model adjustments for age and body mass in otherwise healthy adults (Devaraj et al., 2005). In our study, lying deprivation resulted in an increase of $T N F$ and $I L 1 B$ message abundance regardless of stimulation and IL6 message abundance by nonstimulated whole-blood leukocytes. The increase in these cytokines suggests that cows adapted physiologically to inflammation. A partial link to sleep deprivation in this treatment group is likely based on our prior evidence indicating reductions in sleep states (NREM, REM, drowsing) for lying-deprived cattle but not those roused by human disturbance (Kull et al., 2019). 
Other researchers also have reported increases in TNF, IL1B, or IL6 after a period of sleep deprivation. For instance, increases in TNF, IL1B, and IL6 were observed in the sera of male mice after $36 \mathrm{~h}$ of wakefulness induced by the need to maintain balance on a floating Styrofoam raft (Hu et al., 2003). Increases in IL1B- and TNF-secreted protein by whole-blood leukocytes after stimulation with LPS also were observed in healthy men following 1 night of sleep deprivation where they remained in a sitting position (Born et al., 1997). A recent meta-analysis of experimentally induced sleep deprivation in people, however, did not observe a significant effect of partial or full sleep deprivation on IL6 or TNF (Irwin et al., 2016). The relationship with the current observations must be interpreted with caution because the meta-analysis was restricted to a single time point the morning after sleep deprivation, reflects changes at sera or cellular level, included species that do not exhibit the same sleep states as cattle, and did not include activity level during sleep deprivation as a criterion.
Another factor contributing to the differences in our treatment groups could be the long-duration exercise that occurred with cows standing for $24 \mathrm{~h}$. A link between duration and intensity of exercise and induction of proinflammatory cytokines has been noted in other species (reviewed by Powers and Jackson, 2008). A relevant, recent example was reported in humans who walked 30 to $50 \mathrm{~km} / \mathrm{d}$ for $4 \mathrm{~d}$, where a significant increase in circulating TNF, IL1B, and IL6 was observed after the first day of walking for approximately 7.5 to $8.5 \mathrm{~h}$ (Verheggen et al., 2019). Thus, the exercise associated with standing versus resting for $24 \mathrm{~h}$ could partly explain the increases in proinflammatory cytokine RNA generated by peripheral blood leukocytes. Cows that are standing for prolonged periods of time may also experience swelling as humans do (Tomei et al., 1999), which may also contribute to inflammation. The consequences of extended standing periods on greater proinflammatory cytokine mRNA most likely reflect the combination of stressors, standing and lack of sleep, each of which would have implications regarding dis-

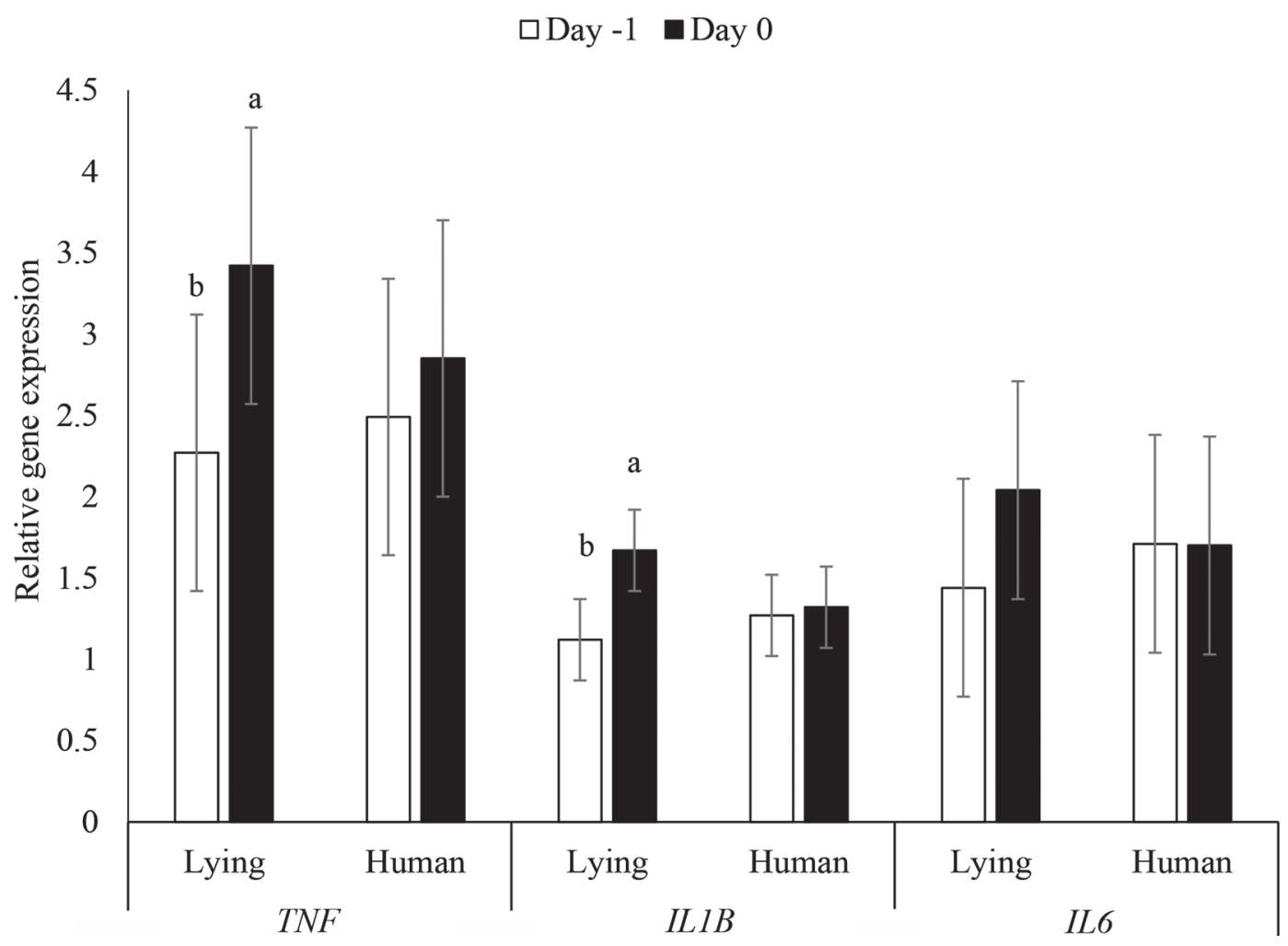

Figure 1. Expression of $T N F, I L 1 B$, and $I L 6$ by whole-blood leukocytes collected from dairy cows on baseline day (d -1 ) and treatment day (d 0) undergoing one of two 24-h treatments: lying deprivation (Lying) or human disturbance (Human). Cytokine expression includes both nonstimulated and LPS-stimulated populations. Gene expression is relative to 2 reference genes: YWHAZ and RPS24. Least squares means and SE are presented for relative gene expression values. Values with different letters $(a, b)$ differ by day within a treatment and cytokine pairing $(P<0.05)$. 

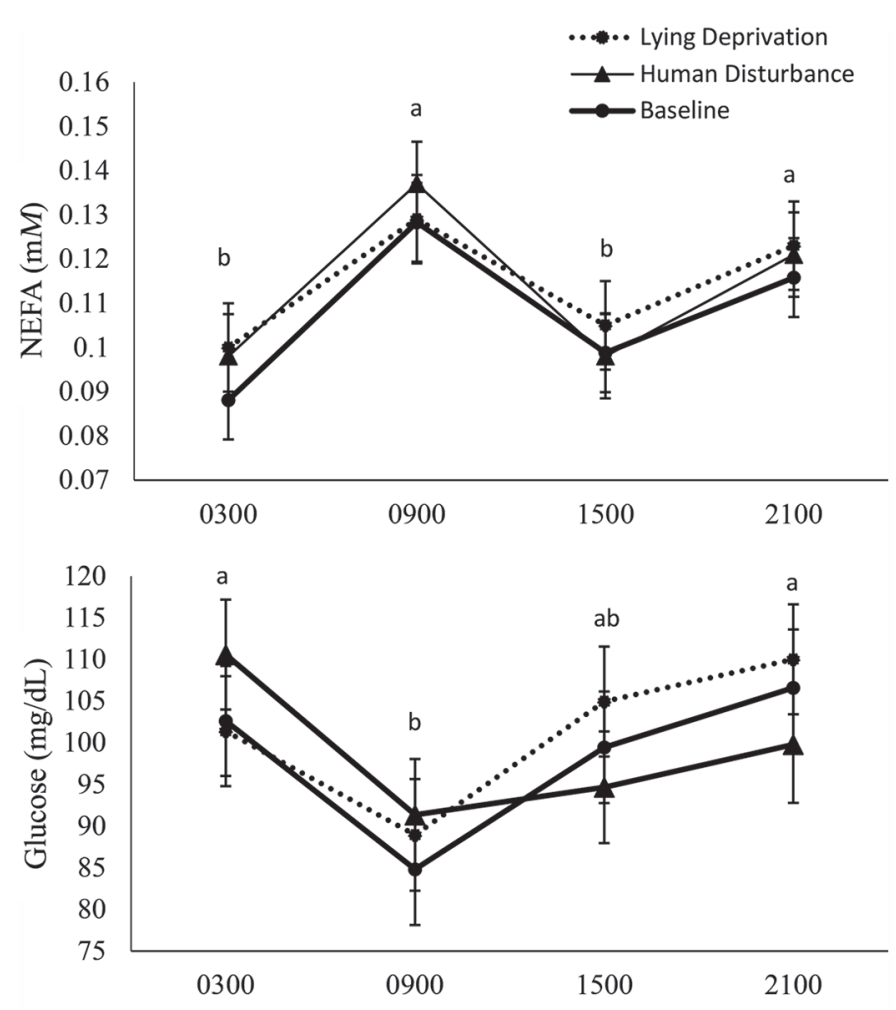

Sampling time of day (h)

Figure 2. Raw means and SE of nonesterified fatty acids (NEFA) and glucose of dairy cows during their 24 -h baseline period $(\mathrm{d}-1)$ and 24 -h treatment period (d 0$)$. The treatment was either human disturbance or lying deprivation. Values with different letters $(\mathrm{a}, \mathrm{b})$ differ relative to other sampling times $(P \leq 0.05)$. Specific days or treatments did not differ, so superscripts are representative only of sampling times.

ease risk when under conditions that promote greater standing times, such as heat stress and overstocking.

Overall, our findings for LPS-stimulated expression of cytokines agree with prior literature (Adams and Czuprynski, 1995; Røntved et al., 2005). However, after $24 \mathrm{~h}$ of lying deprivation, LPS resulted in a significantly greater induction of $T N F$ and $I L 1 B$ RNA but not IL 6 compared with baseline values and human disturbance. The differential effect on these cytokines most likely reflects the cow's physiological adaptations to the combined effects of sleep loss and exercise associated with lying deprivation. A potential mechanism tied to greater induction of proinflammatory cytokines is oxidative stress, as the duration and intensity of exercise promote the induction of free radicals by skeletal muscle and can lead to tissue damage (Powers and Jackson, 2008). A recent study also indicated an increase in oxidative stress within the small intestine of mice after $2 \mathrm{~d}$ of sleep deprivation (Vaccaro et al., 2020). Inflammatory gene expression and leukocyte trafficking patterns dis- play circadian patterns that can be disrupted by relatively short interruptions in sleep patterns (reviewed by Scheiermann et al., 2018). The implication of elevated responsiveness to LPS relative to the health of the animal could have multiple outcomes. The first could be effective clearance of the invading pathogen; the second could be an exaggerated inflammatory response that leads to disproportionate responses to immune triggers.

There was no effect of our treatments on NEFA, but NEFA was affected by time of day. This result is not surprising because NEFA has a diurnal pattern (Ametaj et al., 2009) and can be affected by feeding frequency (Sutton et al., 1988), sampling time, and housing type (Blum et al., 2000). Consistent with other studies, NEFA peaked at $0900 \mathrm{~h}$ and decreased around 0300 and $1500 \mathrm{~h}$ for dairy cows (Nielsen et al., 2003). Concentrations of NEFA were $\leq 0.2 \mathrm{mM}$, indicating that cows were in positive energy balance and within the normal range for cattle (Hammon et al., 2006). It should also be noted that these cows experienced a 3 - $\mathrm{kg}$ decrease in milk production on the day after the lying deprivation treatment, potentially allowing cows to maintain energy balance despite increased energy demands during sleep loss (Kull et al., 2019).

Glucose also changed by time of day but was not affected by treatment. Glucose followed the diurnal pattern reported by Rottman et al. (2014), but appeared to be elevated during both baseline and treatment periods. Results were above the normal 55 to $70 \mathrm{mg} /$ dL range previously reported for lactating dairy cows (Ametaj et al., 2009; Rottman et al., 2014). Glucose can increase during times of stress, such as hoof trimming (Trevisi et al., 2007), transportation (Tarrant et al., 1992; Early and O'Riordan, 2006), heat stress (Wheelock et al., 2010), or surgery (Mudroň et al., 2005). Perhaps cows in our study were under stress throughout the study because they were separated from their group, housed in a novel environment, wore potentially uncomfortable EEG equipment, and had to undergo blood sampling every $6 \mathrm{~h}$. However, NEFA has been reported to increase during times of stress (Collier et al., 1982; Andrews and Walker, 1999), and our values were within the normal range. Thus, it is not clear why glucose was elevated throughout the study or why we did not detect a difference in treatments or periods.

As this was a proof-of-concept study, a main limitation is that our sample of cows is likely not representative of the population of cattle on dairy farms. We specifically selected cows that had a high tolerance to humans and perhaps a higher overall tolerance to a stressful environment. Our results may not be applicable to those that are more anxious or nervous around humans. More research is encouraged to mea- 
sure the effects of sleep deprivation on more vulnerable populations, such as ill cows, postparturient cows, or those with more nervous dispositions. Another main limitation is that cows were kept in very different environments during the treatment and baseline periods that may not be representative of their normal housing (e.g., individually housed on a mattress), which may have caused low-grade stress throughout the trial. We were also unable to measure the effects of our treatments on DMI, which would help in our interpretation of the results for metabolic indicators. We also were unable to determine whether the adaption toward a proinflammatory environment during lying deprivation was driven by sleep loss, greater standing time, or a combination of both. Further research attempting to separate these and other factors is still needed. Inclusion of a systemic marker of inflammation, such as serum amyloid A, TNF, or IL6, collected throughout the day and night before and during recovery in future research also would help establish the extent to which systemic proinflammatory changes occur.

\section{CONCLUSIONS}

Cows that experienced a combination of sleep deprivation and excessive standing time displayed an adaption toward a proinflammatory phenotype based on cytokine message abundance but displayed no differences in metabolic indicators. Our results are applicable only to healthy mid- to high-lactation dairy cows with a relatively high tolerance to human contact. To our knowledge, our results are the first to indicate that short periods of sleep and lying deprivation may have downstream effects on cattle health. The findings of this study also point toward additional mechanisms that may contribute to health issues associated with conditions that promote excessive standing, such as overcrowding, heat stress, and transport stress.

\section{ACKNOWLEDGMENTS}

This work was supported by the USDA National Institute of Food and Agriculture AFRI Exploratory grants program (grant no. 2015-6703024295; Washington, DC). GMP also was supported by the USDA National Institute of Food and Agriculture Capacity Building Grant, NE1748/TN525: Mastitis Resistance to Enhance Dairy Food Safety. We thank the farm staff at the University of Tennessee's Little River Animal and Environmental Unit (Walland, TN) for their assistance and the graduate and undergraduate students at the University of Tennessee (Knoxville) who volunteered their assistance during the project. We also greatly appreciate the expertise of Leszek Wojakiewicz (University of Tennessee, Knoxville) and his aid in completing the cytokine analysis. The authors have not stated any conflicts of interest.

\section{REFERENCES}

Adams, J. L., and C. J. Czuprynski. 1995. Ex vivo induction of TNF- $\alpha$ and IL6 mRNA in bovine whole blood by Mycobacterium paratuberculosis and mycobacterial cell wall components. Microb. Pathog. 19:19-29. https://doi.org/10.1006/mpat.1995.0041.

Alhussien, M., M. Kaur, P. Manjari, S. P. Kimothi, A. K. Mohanty, and A. K. Dang. 2015. A comparative study on the blood and milk cell counts of healthy, subclinical, and clinical mastitis Karan Fries cows. Vet. World 8:685-689. https://doi.org/10.14202/vetworld .2015.685-689.

Ametaj, B. N., D. G. V. Emmanuel, Q. Zebeli, and S. M. Dunn. 2009. Feeding high proportions of barley grain in a total mixed ration perturbs diurnal patterns of plasma metabolites in lactating dairy cows. J. Dairy Sci. 92:1084-1091. https://doi.org/10.3168/jds.2008 $-1465$.

Andrews, R. C., and B. R. Walker. 1999. Glucocorticoids and insulin resistance: Old hormones, new targets. Clin. Sci. (Lond.) 96:513523. https://doi.org/10.1042/cs0960513.

Blum, J. W., R. M. Bruckmaier, P.-Y. Vacher, A. Münger, and F. Jans. 2000. Twenty-four-hour patterns of hormones and metabolites in week 9 and 19 of lactation in high-yielding dairy cows fed triglycerides and free fatty acids. J. Vet. Med. A Physiol. Pathol. Clin. Med. 47:43-60. https://doi.org/10.1046/j.1439-0442.2000 .00266.x.

Born, J., T. Lange, K. Hansen, M. Molle, and H.-L. Fehm. 1997. Effects of sleep and circadian rhythm on human circulating immune cells. J. Immunol. 158:4454-4464.

Bradford, B. J., K. Yuan, J. K. Farney, L. K. Mamedova, and A. J. Carpenter. 2015. Invited review: Inflammation during the transition to lactation: New adventures with an old flame. J. Dairy Sci. 98:6631-6650. https://doi.org/10.3168/jds.2015-9683.

Chennaoui, M., D. Gomez-Merino, C. Drogou, H. Geoffroy, G. Dispersyn, C. Langrume, S. Ciret, T. Gallopin, and F. Sauvet. 2015. Effects of exercise on brain and peripheral inflammatory biomarkers induced by total sleep deprivation in rats. J. Inflamm. (Lond.) 12:56. https://doi.org/10.1186/s12950-015-0102-3.

Cohen, S., W. J. Doyle, C. M. Alper, D. Janicki-Deverts, and R. B. Turner. 2009. Sleep habits and susceptibility to the common cold. Arch. Intern. Med. 169:62-67. https://doi.org/10.1001/ archinternmed.2008.505.

Collier, R. J., S. Doelger, H. Head, W. Thatcher, and C. Wilcox. 1982. Effects of heat stress during pregnancy on maternal hormone concentrations, calf birth weight and postpartum milk yield of Holstein cows. J. Anim. Sci. 54:309-319. https://doi.org/10.2527/ jas1982.542309x.

Devaraj, S., G. O'Keefe, and I. Jialal. 2005. Defining the proinflammatory phenotype using high sensitive C-reactive protein levels as the biomarker. J. Clin. Endocrinol. Metab. 90:4549-4554. https:// doi.org/10.1210/jc.2005-0069.

Donga, E., M. van Dijk, J. G. van Dijk, N. R. Biermasz, G.-J. Lammers, K. W. van Kralingen, E. P. Corssmit, and J. A. Romijn. 2010. A single night of partial sleep deprivation induces insulin resistance in multiple metabolic pathways in healthy subjects. J. Clin. Endocrinol. Metab. 95:2963-2968. https://doi.org/10.1210/ jc.2009-2430.

Early, B., and E. O'Riordan. 2006. Effects on transporting bulls at different space allowance on physiological, haematological and immunological responses to 12 -h journey by road. Ir. J. Agric. Food Res. 45:39-50. 
Galvão, K. N. 2018. Postpartum uterine diseases in dairy cows. Anim. Reprod. 9:290-296.

Gottlieb, D. J., N. M. Punjabi, A. B. Newman, H. E. Resnick, S. Redline, C. M. Baldwin, and F. J. Nieto. 2005. Association of sleep time with diabetes mellitus and impaired glucose tolerance. Arch. Intern. Med. 165:863-867. https://doi.org/10.1001/archinte .165.8.863.

Grandner, M. A., L. Hale, M. Moore, and N. P. Patel. 2010. Mortality associated with short sleep duration: The evidence, the possible mechanisms, and the future. Sleep Med. Rev. 14:191-203. https:// doi.org/10.1016/j.smrv.2009.07.006.

Hammon, D. S., I. M. Evjen, T. R. Dhiman, J. P. Goff, and J. L. Walters. 2006. Neutrophil function and energy status in Holstein cows with uterine health disorders. Vet. Immunol. Immunopathol. 113:21-29. https://doi.org/10.1016/j.vetimm.2006.03.022.

Hu, J., Z. Chen, C. Gorczynski, L. Gorczynski, Y. Kai, L. Lee, J. Manuel, and R. Gorczynski. 2003. Sleep-deprived mice show altered cytokine production manifest by perturbations in serum IL1ra, TNFa, and IL6 levels. Brain Behav. Immun. 17:498-504. https:// doi.org/10.1016/j.bbi.2003.03.001.

Huzzey, J. M., D. M. Veira, D. M. Weary, and M. A. G. Von Keyserlingk. 2007. Prepartum behavior and dry matter intake identify dairy cows at risk for metritis. J. Dairy Sci. 90:3220-3233. https:/ /doi.org/10.3168/jds.2006-807.

Irwin, M. R., R. Olmstead, and J. E. Carroll. 2016. Sleep disturbance, sleep duration, and inflammation: A systematic review and metaanalysis of cohort studies and experimental sleep deprivation. Biol. Psychiatry 80:40-52. https://doi.org/10.1016/j.biopsych.2015.05 .014 .

Irwin, M. R., M. Wang, C. O. Campomayor, A. Collado-Hidalgo, and S. Cole. 2006. Sleep deprivation and activation of morning levels of cellular and genomic markers of inflammation. Arch. Intern. Med. 166:1756-1762. https://doi.org/10.1001/archinte.166.16.1756.

Ito, K., M. A. G. Von Keyserlingk, S. J. LeBlanc, and D. M. Weary. 2010. Lying behavior as an indicator of lameness in dairy cows. J. Dairy Sci. 93:3553-3560. https://doi.org/10.3168/jds.2009-2951.

Kull, J. A., K. L. Proudfoot, G. M. Pighetti, J. M. Bewley, B. F. O'Hara, K. D. Donohue, and P. D. Krawczel. 2019. Effects of acute lying and sleep deprivation on the behavior of lactating dairy cows. PLoS One 14:e0212823. https://doi.org/10.1371/journal.pone .0212823 .

Lensink, B. J., C. G. van Reenen, B. Engel, T. B. Rodenburg, and I. Veissier. 2003. Repeatability and reliability of an approach test to determine calves' responsiveness to humans: A brief report. Appl. Anim. Behav. Sci. 83:325-330. https://doi.org/10.1016/S0168 $-1591(03) 00138-2$.

Levkut, M., J. Pistl, V. Revajova, J. Choma, M. Levkutova, and V. David. 2002. Comparison of immune parameters in cows with normal and prolonged involution time of uterus. Veterinarni Medicine Košice, Slovak Republic 47:277-282.

Livak, K. J., and T. D. Schmittgen. 2001. Analysis of relative gene expression data using real-time quantitative PCR and the $2^{-\triangle \Delta \mathrm{CT}}$ method. Methods 25:402-408. https://doi.org/10.1006/meth.2001 1262 .

McPherson, R. 2001. Laboratory evaluation of immunoglobulin function and humoral immunity. Pages 878-891 in Clinical Diagnosis and Management by Laboratory Methods. 20th ed. J. B. Henry, ed. Saunders, Philadelphia, PA.

Metz, J. H. M. 1985. The reaction of cows to a short-term deprivation of lying. Appl. Anim. Behav. Sci. 13:301-307. https://doi.org/10 .1016/0168-1591(85)90010-3.

Motivala, S. J., and M. R. Irwin. 2007. Sleep and immunity: Cytokine pathways linking sleep and health outcomes. Curr. Dir. Psychol. Sci. 16:21-25.

Mudroň, P., J. Rehage, H. Sallmann, M. Höltershinken, and H. Scholz. 2005. Stress response in dairy cows related to different blood glucose. Acta Vet. Brno 74:37-42. https://doi.org/10.2754/ avb200574010037.

Munksgaard, L., and H. B. Simonsen. 1996. Behavioral and pituitary adrenal-axis responses of dairy cows to social isolation and depri- vation of lying down. J. Anim. Sci. 74:769-778. https://doi.org/10 $.2527 / 1996.744769 x$

Nielsen, N. I., K. L. Ingvartsen, and T. Larsen. 2003. Diurnal variation and the effect of feed restriction on plasma and milk metabolites in TMR-fed dairy cows. J. Vet. Med. A Physiol. Pathol. Clin. Med. 50:88-97. https://doi.org/10.1046/j.1439-0442.2003.00496.x.

Ospina, P. A., D. V. Nydam, T. Stokol, and T. R. Overton. 2010. Associations of elevated nonesterified fatty acids and $\beta$-hydroxybutyrate concentrations with early lactation reproductive performance and milk production in transition dairy cattle in the northeastern United States. J. Dairy Sci. 93:1596-1603. https://doi.org/10.3168/jds .2009-2852.

Overton, T. R., J. A. A. McArt, and D. V. Nydam. 2017. A 100year review: Metabolic health indicators and management of dairy cattle. J. Dairy Sci. 100:10398-10417. https://doi.org/10.3168/jds .2017-13054.

Powers, S. K., and M. J. Jackson. 2008. Exercise induced oxidative stress: Cellular mechanisms and impact on muscle force production. Physiol. Rev. 88:1243-1276. https://doi.org/10.1152/physrev .00031 .2007 .

Røntved, C. M., J. B. Andersen, J. Dernfalk, and K. L. Ingvartsen. 2005. Effects of diet energy density and milking frequency in early lactation on tumor necrosis factor-alpha responsiveness in dairy cows. Vet. Immunol. Immunopathol. 104:171-181. https://doi.org/ 10.1016/j.vetimm.2004.11.001.

Rottman, L. W., Y. Ying, K. Zhou, P. A. Bartell, and K. J. Harvatine. 2014. The daily rhythm of milk synthesis is dependent on the timing of feed intake in dairy cows. Physiol. Rep. 2:e12049. https:// doi.org/10.14814/phy2.12049.

Ruckebusch, Y. 1972. The relevance of drowsiness in the circadian cycle of farm animals. Anim. Behav. 20:637-643.

Sabanayagam, C., and A. Shankar. 2010. Sleep duration and cardiovascular disease: Results from the National Health Interview Survey. Sleep 33:1037-1042. https://doi.org/10.1093/sleep/33.8.1037.

Schalm, O. W. 1961. Page 155 in Veterinary Hematology. Lea and Febiger.

Scheiermann, C., J. Gibbs, L. Ince, and A. Loudon. 2018. Clocking in to immunity. Nat. Rev. Immunol. 18:423-437. https://doi.org/10 .1038/s41577-018-0008-4.

Schütz, K. E., N. R. Cox, and L. R. Matthews. 2008. How important is shade to dairy cattle? Choice between shade or lying following different levels of lying deprivation. Appl. Anim. Behav. Sci. 114:307-318. https://doi.org/10.1016/j.applanim.2008.04.001.

Sutton, J. D., I. C. Hart, S. V. Morant, E. Schuller, and A. D. Simmonds. 1988. Feeding frequency for lactating cows: Diurnal patterns of hormones and metabolites in peripheral blood in relation to milk-fat concentration. Br. J. Nutr. 60:265-274. https://doi .org/10.1079/BJN19880098

Tarrant, P., F. Kenny, D. Harrington, and M. Murphy. 1992. Long distance transportation of steers to slaughter: Effect of stocking density on physiology, behaviour and carcass quality. Livest. Prod. Sci. 30:223-238. https://doi.org/10.1016/S0301-6226(06)80012-6.

Ternman, E., L. Hänninen, M. Pastell, S. Agenäs, and P. P. Nielsen. 2012. Sleep in dairy cows recorded with a non-invasive EEG technique. Appl. Anim. Behav. Sci. 140:25-32. https://doi.org/10 .1016/j.applanim.2012.05.005.

Ternman, E., E. Nilsson, P. P. Nielsen, M. Pastell, L. Hänninen, and S. Agenäs. 2019. Rapid eye movement sleep time in dairy cows changes during the lactation cycle. J. Dairy Sci. 102:5458-5465. https://doi.org/10.3168/jds.2018-15950.

Ternman, E., M. Pastell, S. Agenäs, C. Strasser, C. Winckler, P. P. Nielsen, and L. Hänninen. 2014. Agreement between different sleep states and behaviour indicators in dairy cows. Appl. Anim. Behav. Sci. 160:12-18. https://doi.org/10.1016/j.applanim.2014.08.014.

Tomei, F., T. P. Baccolo, E. Tomao, S. Palmi, and M. V. Rosati. 1999. Chronic venous disorders and occupation. Am. J. Ind. Med. 36:653-665. https://doi.org/10.1002/(SICI)1097-0274(199912)36 $6<653::$ AID-AJIM8 $>3.0$. CO $: 2-\mathrm{P}$

Trevisi, E., R. Lombardelli, A. Minuti, and G. Bertoni. 2007. Change of digesta passage rate in dairy cows after different acute stress situations. Ital. J. Anim. Sci. 6(Suppl. 1):377-379. 
Untergasser, A., I. Cutcutache, T. Koressaar, J. Ye, B. C. Faircloth, M. Remm, and S. G. Rozen. 2012. Primer3-New capabilities and interfaces. Nucleic Acids Res. 40:e115. https://doi.org/10.1093/ nar/gks596.

Vaccaro, A., Y. Kaplan Dor, K. Nambara, E. A. Pollina, C. Lin, M. E. Greenberg, and D. Rogulja. 2020. Sleep loss can cause death through accumulation of reactive oxygen species in the gut. Cell 181:1307-1328. https://doi.org/10.1016/j.cell.2020.04.049.

van Leeuwen, W. M., M. Lehto, P. Karisola, H. Lindholm, R. Luukkonen, M. Sallinen, M. Härmä, T. Porkka-Heiskanen, and H. Alenius. 2009. Sleep restriction increases the risk of developing cardiovascular diseases by augmenting proinflammatory responses through IL17 and CRP. PLoS One 4:e4589. https://doi.org/10 .1371/journal.pone.0004589.

Vandesompele, J., K. De Preter, F. Pattyn, B. Poppe, N. Van Roy, A. De Paepe, and F. Speleman. 2002. Accurate normalization of real-time quantitative RT-PCR data by geometric averaging of multiple internal control genes. Genome Biol. 3:research0034-1.

Verheggen, R. J. H. M., T. M. H. Eijsvogels, M. Catoire, R. Terink, R. Ramakers, C. C. W. G. Bongers, M. Mensink, A. R. M. M. Her- mus, D. H. J. Thijssen, and M. T. E. Hopman. 2019. Cytokine responses to repeated, prolonged walking in lean versus overweight/ obese individuals. J. Sci. Med. Sport 22:196-200. https://doi.org/ 10.1016/j.jsams.2018.07.019.

Wheelock, J. B., R. P. Rhoads, M. J. VanBaale, S. R. Sanders, and L. H. Baumgard. 2010. Effects of heat stress on energetic metabolism in lactating Holstein cows. J. Dairy Sci. 93:644-655. https://doi .org/10.3168/jds.2009-2295.

\section{ORCIDS}

K. L. Proudfoot (ํ) https://orcid.org/0000-0001-5877-2431

J. A. Kull ๑ https://orcid.org/0000-0002-2186-1358

P. D. Krawczel $\odot$ https://orcid.org/0000-0002-9867-2280

J. M. Bewley (1) https://orcid.org/0000-0002-7347-2741

B. F. O'Hara ๑ https://orcid.org/0000-0002-5553-8209

K. D. Donohue (®) https://orcid.org/0000-0003-4423-6296

G. M. Pighetti ৫ https://orcid.org/0000-0003-0947-2381 